\title{
Hot Water Treatment for Chilling Injury Reduction of Astringent 'Rojo Brillante' Persimmon at Different Maturity Stages
}

\author{
Cristina Besada, Alejandra Salvador ${ }^{1}$, Lucía Arnal, \\ and Jose María Martínez-Jávega \\ Departamento de Postcosecha, Instituto Valenciano de Investigaciones \\ Agrarias, Carretera Monacada-Náquera, Km, 4.5, 46113, Valencia, Spain
}

Additional index words. fruit firmness, hot treatment, browning, cracking, cold storage, maturity stage

\begin{abstract}
The effects of hot water treatments (HWTs) on chilling injury (CI) of 'Rojo Brillante' persimmon treated at different maturity stages and stored at $1^{\circ} \mathrm{C}$ have been investigated. HWT temperatures ranging from 45 to $55^{\circ} \mathrm{C}$ were applied for periods of time of between 2.5 and $40 \mathrm{~min}$. Reduction of CI by HWT depended on the maturity stage. HWTs reduced softening when they were applied to fruit at an early stage of maturity, but caused skin cracking and skin browning in middle and advanced stages of maturity. Incidence and severity of these disorders increased as HWT temperatures and treatment times increased and in more mature fruit.
\end{abstract}

'Rojo Brillante' persimmon, like other cultivars such as Fuyu or Suruga (Collins and Tisdell, 1995), is chilling-sensitive. Previous reports for this cultivar showed that these fruit are sensitive at temperatures below $11^{\circ} \mathrm{C}$; the main chilling injury $(\mathrm{CI})$ symptom is softening when fruit are transferred to higher temperature (Arnal and Del Rio, 2004; Salvador et al., 2004). Like other fruit, 'Rojo Brillante' persimmon showed higher sensitivity to low temperatures when they were picked at early maturity stages (Salvador et al., 2005, 2006).

In persimmon fruit, heat treatments have been evaluated mainly in 'Fuyu', a nonastringent cultivar, in which they reduced CIassociated symptoms of flesh gelling or flesh softening. This effect was observed when fruit were treated with hot air treatments (HTs) (Woolf et al., 1997a, 1997b) or with hot water treatments (HWTs) (Burmeister et al., 1997; Lay-Yee et al., 1997). Moreover, other positive effects of HWT on persimmon fruit such as disinfestation in 'Fuyu' were reported (Lay-Yee et al., 1997). There are no studies on the effect of HWTs on any astringent cultivar of persimmon.

The purpose of this study was to determine the effect of the time and temperature of HWT on CI of 'Rojo Brillante' persimmon from different maturity stages.

\section{Material and Methods}

Plant material and treatments. Persimmon fruit, cv. Rojo Brillante, in three different stages of commercial maturity were

Received for publication 14 Mar. 2008. Accepted for publication 5 Aug. 2008.

${ }^{1}$ To whom reprint requests should be addressed; e-mail asalvado@ivia.es picked at L'Alcudia (Valencia, Spain) from October to December. Three experiments were performed corresponding to fruit picked at early harvest $(\mathrm{H} 1)$, midharvest $(\mathrm{H} 2)$, and late harvest $(\mathrm{H} 3)$. Fruit presented color index of 2.3 (yellow-orange), 17.4 (orange), and 23.4 (orange-red) and firmness values of $47 \mathrm{~N}, 33 \mathrm{~N}$, and $21 \mathrm{~N}$, respectively.

After harvest, fruit were transported immediately to the experimental station of the Instituto Valenciano de Investigaciones Agrarias, where they were carefully selected for uniformity of size, color, and absence of defects. After that, fruit were kept at room temperature $\left(15+-1{ }^{\circ} \mathrm{C}\right)$. The day after harvesting, the fruit were randomly separated into different lots (20 fruit per lot) corresponding to the following HWTs: 45,50 or $55{ }^{\circ} \mathrm{C}$ for $2.5,5,10,20$, or $30 \mathrm{~min}$. Fruit from $\mathrm{H} 2$ and $\mathrm{H} 3 \mathrm{w}$ were also treated for $40 \mathrm{~min}$. Nontreated fruit, control fruit, were directly stored at $1{ }^{\circ} \mathrm{C}$.

HWTs were carried out by placing fruit in 18-L stainless steel grid baskets and submerging them in water heated to the test temperature for target time. A 250 -L stainless steel water tank fitted with two $4.5-\mathrm{kW}$ electric resistance heaters and a thermostat was used. After HWTs, fruit were kept at room temperature for $5 \mathrm{~min}$ and carefully dried with paper; after 1.5 to $2 \mathrm{~h}$, fruit from each treatment were transferred to $1{ }^{\circ} \mathrm{C}(90 \%$ relative humidity) for up to $32 \mathrm{~d}$. At the end of storage, the fruit were kept at room temperature for $12 \mathrm{~h}$ before astringency removal treatment in closed containers under standard conditions $\left(95 \%\right.$ to $98 \% \mathrm{CO}_{2}$ for $24 \mathrm{~h}$ at $20{ }^{\circ} \mathrm{C}$ ) by streaming the air out with $\mathrm{CO}_{2}$. Then the fruit were transferred to $20{ }^{\circ} \mathrm{C}$ to simulate a shelf life period of $4 \mathrm{~d}$.

Fruit assessments. Immediately after HWTs, fruit were evaluated visually for external damage. Measurements of flesh firmness, external color, and external or internal disorders were taken after the shelf life period.

Flesh firmness was determined by a Texturometer Instron Universal Machine model 4301 (Instron Corp., Canton, MA) using an 8-mm flat plunger. Fruit firmness values are an average from 20 fruit. Results were expressed as the load in Newtons (N) required to break the flesh of each fruit on opposite sides after peel removal.

Skin color was evaluated by a Minolta Colorimeter (Model CR-300; Ramsey, NY) on 20 fruit. 'L', 'a', 'b' Hunter parameters were measured and results were expressed as a skin color index: (1000a)/(Lb) (Salvador et al., 2004).

Incidence of external and internal disorders was evaluated visually as absent or present in 20 fruit per treatment, and it was expressed as percentage of affected fruit; intensity of external disorder was defined as slight (affected surface less than $10 \%)$, medium $(10 \%$ to $50 \%$ affected surface), or severe (affected surface greater than $50 \%$ ).

Data were subjected to analysis of variance and least significant difference at the 5\% level was used to compare means using Statgraphics plus 4.1 (StatPoint, Herndon, VA).

\section{Results}

Early harvested fruit (H1). No external damage was detected immediately after fruit treatments. As mentioned previously, the main CI symptom is a drastic reduction in firmness when the fruit is transferred from low to shelf life temperature. After $32 \mathrm{~d}$ at $1{ }^{\circ} \mathrm{C}$ plus shelf life, control fruit softened to noncommercial values of firmness $[10 \mathrm{~N}$ (Salvador et al., 2004)] (Fig. 1). Firmness of fruit from the HWT of $45^{\circ} \mathrm{C}$ for 2.5 min was similar to that of control fruit, whereas fruit were firmer after 5- or 10-min treatments. Fruit treated for 20 or $30 \mathrm{~min}$ suffered significantly slighter softening, reaching firmness values of $25 \mathrm{~N}$ and $35 \mathrm{~N}$, respectively.

Fruit submitted to a HWT at $50{ }^{\circ} \mathrm{C}$ showed less softening than the control fruit; even when the treatment lasted for $2.5 \mathrm{~min}$, firmness values were close to $10 \mathrm{~N}$. The longer the $50{ }^{\circ} \mathrm{C}$ HWT lasted, the less soft the fruit. In this way, $50{ }^{\circ} \mathrm{C}$ HWTs for 20 or 30 min resulted in $39 \mathrm{~N}$ or $43 \mathrm{~N}$ values of firmness, respectively, which were close to values at harvest $(47 \mathrm{~N})$.

Short-time fruit treatments at $55{ }^{\circ} \mathrm{C}$, for $2.5 \mathrm{~min}$ or $5 \mathrm{~min}$, markedly reduced flesh softening, because fruit showed firmness values higher than $10 \mathrm{~N}$. Longer-lasting treatments resulted in firmer fruit close to 40 N. Nevertheless, an external disorder, skin browning around the calyx, was exhibited after shelf life by fruit treated at $55{ }^{\circ} \mathrm{C}$ for more than $2.5 \mathrm{~min}$ (data not shown). The incidence and severity of this external disorder were higher the longer the $55{ }^{\circ} \mathrm{C}$ HWT lasted, ranging from $21 \%$ of damaged 

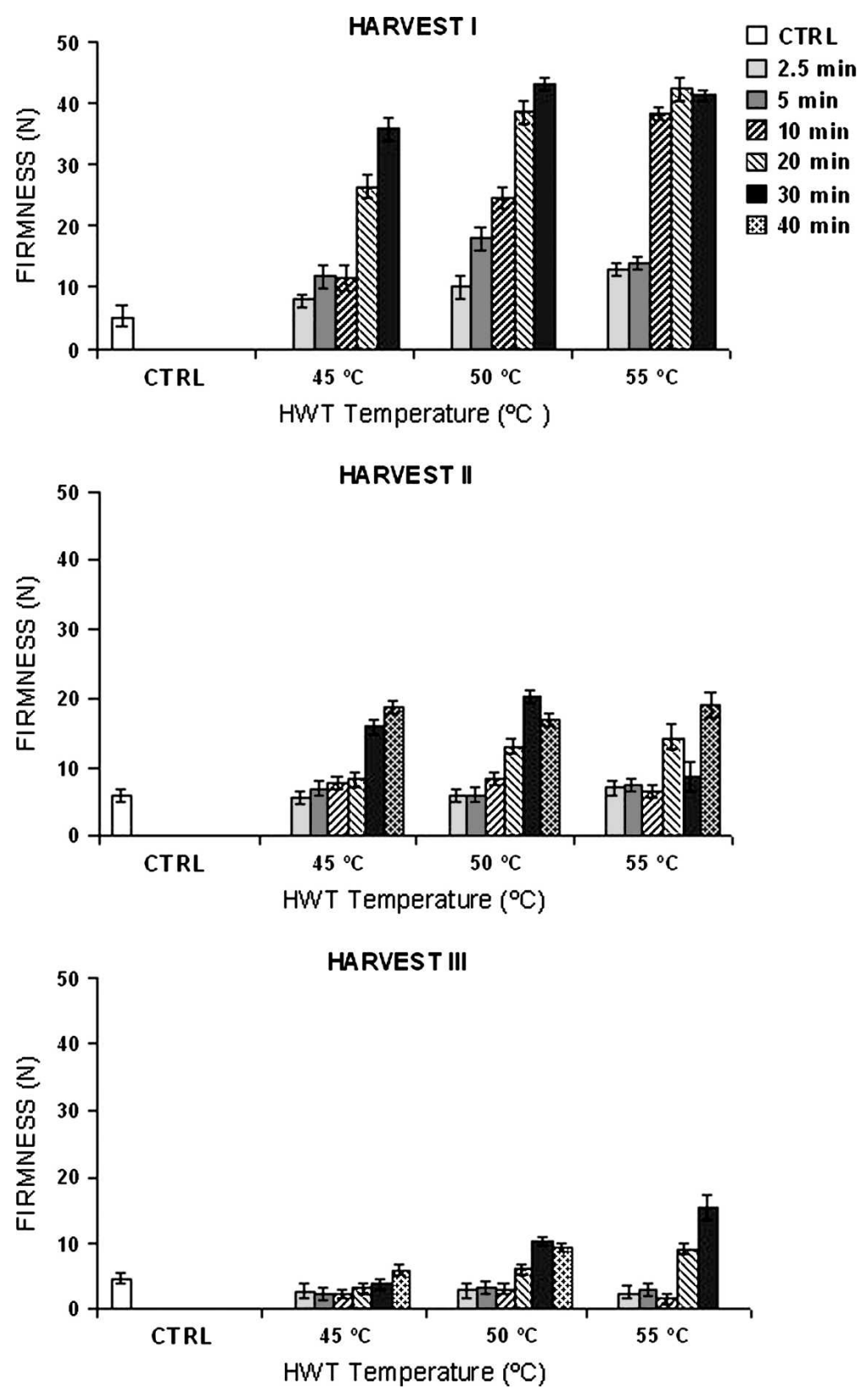

Fig. 1. Effect of application of different hot water treatments, temperature $\left({ }^{\circ} \mathrm{C}\right)$ and duration (minutes), on flesh firmness (N) of persimmon fruit picked at Harvest I, Harvest II, and Harvest III after $32 \mathrm{~d}$ stored at $1{ }^{\circ} \mathrm{C}+4 \mathrm{~d}$ at $20^{\circ} \mathrm{C}$. Vertical bars represent least significant different intervals $(P=0.05)$.

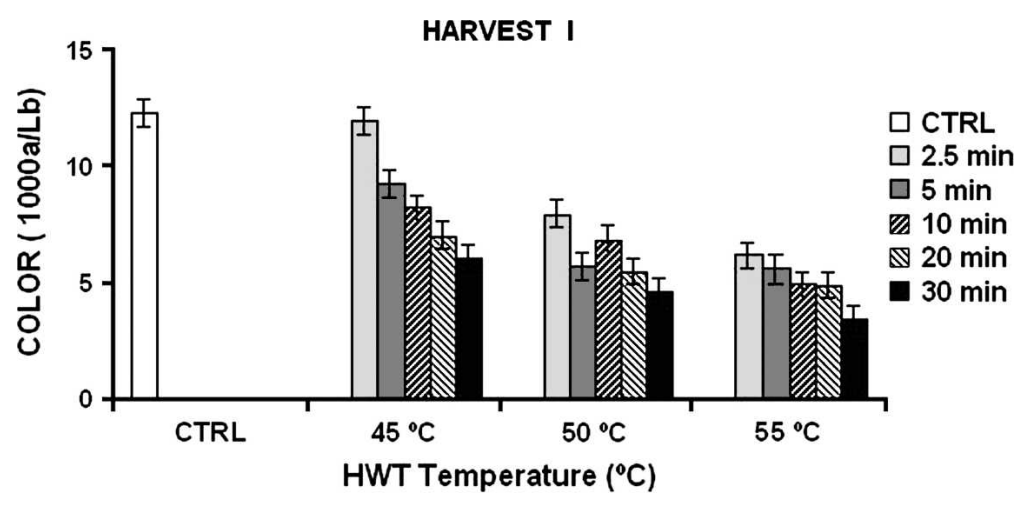

Fig. 2. Effect of application of different hot water treatments, temperature $\left({ }^{\circ} \mathrm{C}\right)$ and duration (minutes), on color index $(1000 \mathrm{a} / \mathrm{Lb})$ of persimmon fruit picked at Harvest I after $32 \mathrm{~d}$ stored at $1{ }^{\circ} \mathrm{C}+4 \mathrm{~d}$ at $20^{\circ} \mathrm{C}$. Vertical bars represent least significant different intervals $(P=0.05)$. fruit for a treatment of $5 \mathrm{~min}$ to $74 \%$ for one of $30 \mathrm{~min}$. These $55{ }^{\circ} \mathrm{C}$ treatments, which damaged fruit externally, also caused internal disorder as outer flesh browning (browning of the outer $1 \mathrm{~cm}$ flesh tissue). The $55^{\circ} \mathrm{C}$ treatment caused a visual dehydration of the calyx, which was more evident the longer the treatment lasted. No external or internal disorders were observed in fruit treated at 45 or $50^{\circ} \mathrm{C}$.

Regarding color index, HWTs delayed the color fruit evolution from yellow-orange to orange (Fig. 2). This delay was associated with an increase in treatment time and temperature; fruit treated at all tested temperatures for 20 or 30 min showed color index values lower than 7 .

Midharvested fruit (H2). Fruit from every HWT, except for the one carried out at $45^{\circ} \mathrm{C}$ for 2.5 and $5 \mathrm{~min}$, unexpectedly showed external damage immediately after hot water application. This heat damage appeared in the form of skin cracking. The higher the HWT temperature and the longer the treatment time, the higher the percentage of affected fruit and the greater the damage intensity (Fig. 3).

After cold storage plus shelf life, every HWT that lasted for no more than $10 \mathrm{~min}$ resulted in very low firmness values, similar to the control fruit (Fig. 1). An HWT of over $10 \mathrm{~min}$ resulted in high firmness values of close to $20 \mathrm{~N}$ in most of the tested HWTs regardless of the assayed temperature. Nevertheless, high firmness values were not associated with the alleviation of CI, but were related to heat damage. It could be explained by the fact that these treatments produced a compacted area of flesh around the cracking because of flesh dehydration.

As happened in the $\mathrm{H} 1$ experiment, fruit treated at $55{ }^{\circ} \mathrm{C}$ showed external browning around the calyx and internal damage, both of which get more intensive the longer the treatment lasts.

The external color index of fruit treated at 45 or $50{ }^{\circ} \mathrm{C}$ was not significantly different when compared with the control fruit (data not shown).

Late-harvested fruit (H3). As is the case with midharvested fruit $(\mathrm{H} 2)$, fruit from $\mathrm{H} 3$ showed skin cracking immediately after HWT applications (Fig. 3); the higher the HWT temperature and longer the treatment time, the more intense the skin cracking. This disorder manifestation in this stage was more accentuated than in $\mathrm{H} 2$, and even treatment at $45{ }^{\circ} \mathrm{C}$ for $2.5 \mathrm{~min}$ or $5 \mathrm{~min}$ caused this damage. Fruit treated at 50 and $55^{\circ} \mathrm{C}$ showed internal damage as outer flesh browning and compacting as well as external browning that was observed all around the skin of the fruit (Fig. 4).

After $1{ }^{\circ} \mathrm{C}$ storage plus shelf life, the control fruit showed firmness values of $5 \mathrm{~N}$ (Fig. 1). Fruit treated at $45{ }^{\circ} \mathrm{C}$ did not show differences in firmness and color with respect to the control fruit, but skin cracking also appeared in fruit from these treatments.

Although treatments applied at 50 and $55{ }^{\circ} \mathrm{C}$ for over $10 \mathrm{~min}$ resulted in fruit with 

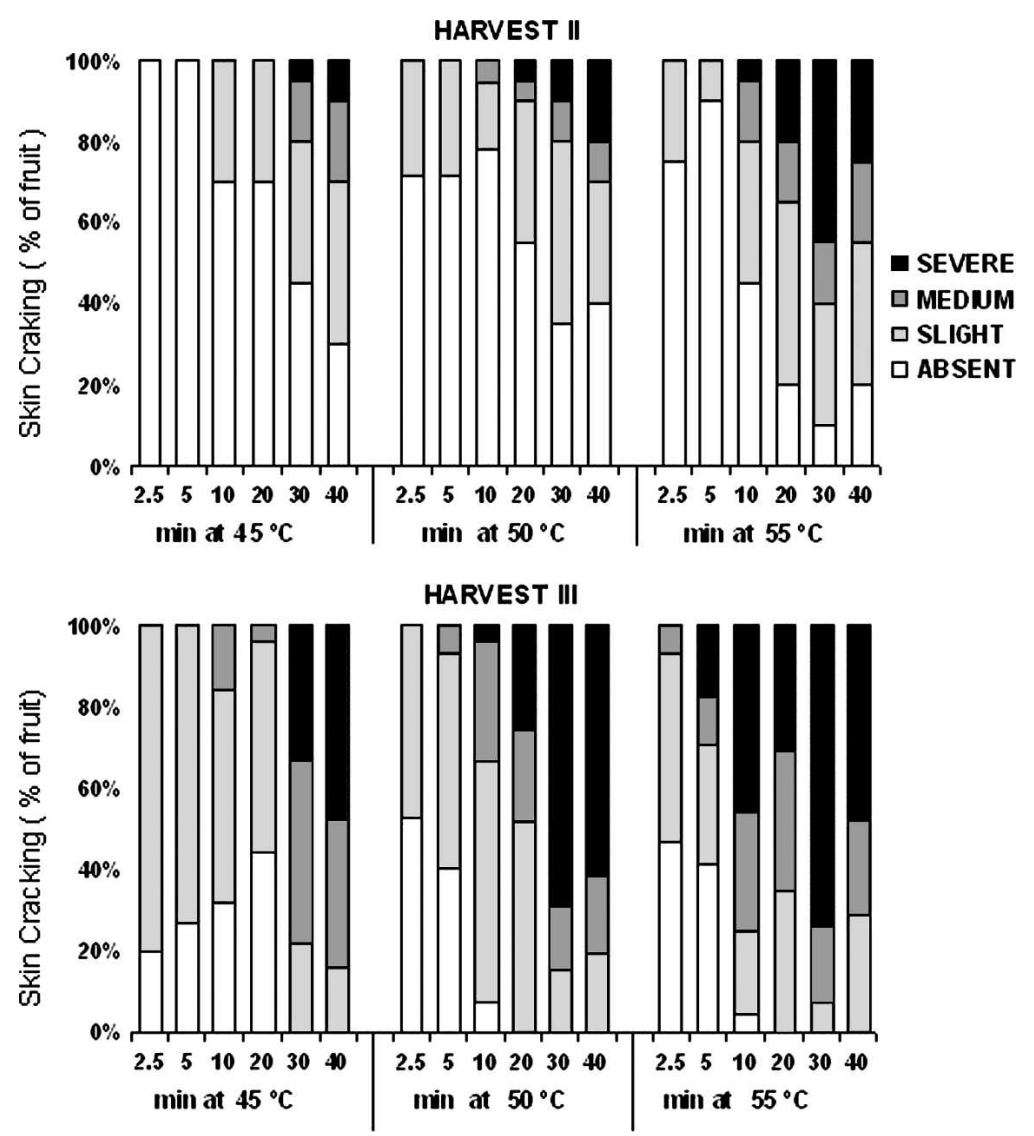

Fig. 3. Incidence (percent of fruit) and severity of skin cracking just after application of different hot water treatments, temperature $\left({ }^{\circ} \mathrm{C}\right)$ and duration (minutes), on persimmon fruit picked at Harvest II and Harvest III.

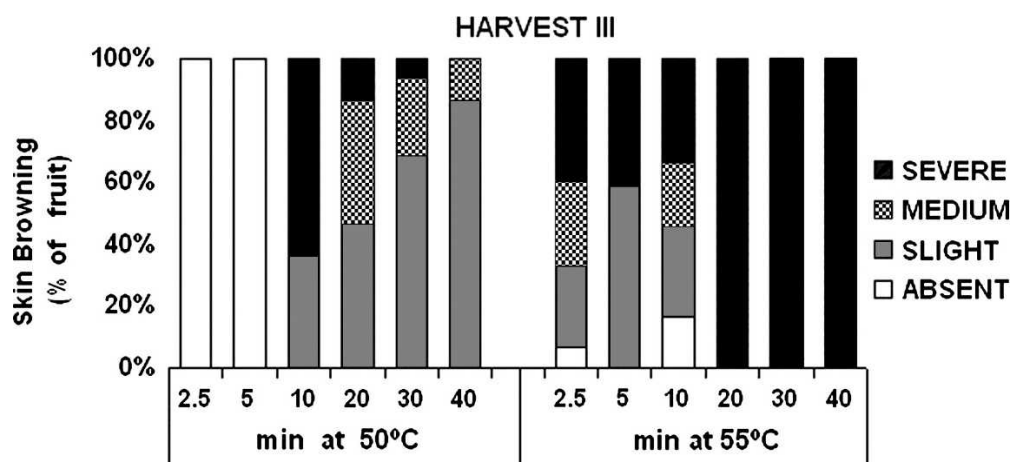

Fig. 4. Incidence (percent of fruit) and severity of skin browning just after application of different hot water treatments, temperature $\left({ }^{\circ} \mathrm{C}\right)$ and duration (minutes), on persimmon fruit picked at Harvest III.

firmness values higher than those of the control fruit, these high values were associated with the heat damage as happened in fruit from $\mathrm{H} 2$.

\section{Discussion}

The response of persimmon cv. Rojo Brillante to HWTs $\left(45,50\right.$, or $55^{\circ} \mathrm{C}$ for 2.5 , $5,10,20,30$ or $40 \mathrm{~min}$ ) depended to a great extent on maturity stage of the fruit. HWTs applied to fruit harvested at an early maturity stage (H1) alleviated CI, preserving fruit firmness, whereas HWTs applied to fruit in more advanced stages of maturity ( $\mathrm{H} 2$ and H3) caused heat damage to fruit and did not reduce CI. Mulas and Schirra (2007) reported that preharvest factors such as season and maturity stage may have a critical effect on the efficacy of heat treatments, especially for those crops that are very susceptible to developing CI or heat damage.

In fruit harvested during the early maturity stage (H1), all HWTs reduced softening, which was a consequence of low-temperature sensitivity. Only those treatments applied for over $2.5 \mathrm{~min}$ at the highest temperature, $55^{\circ} \mathrm{C}$, caused external and internal browning.
'Rojo Brillante' shows the greatest sensitivity to low temperatures during early stages of maturity (Salvador et al., 2005, 2006). For this reason, the effect observed in the present work is especially interesting, because HWT could become a possible alternative to prolonging low-temperature fruit storage. Shorter HWTs at higher temperatures were required to obtain this effect. This interaction between the length of treatment time and temperature agrees with that found in previous works with 'Fuyu' (Burmeister et al., 1997; Lay-Yee et al., 1997) in which heat treatments alleviated flesh gelling and loss of firmness.

In fruit harvested at middle $(\mathrm{H} 2)$ or later (H3) maturity stages, HWT of 45,50 , and $55^{\circ} \mathrm{C}$ had a negative effect immediately after being applied, because they caused the irreversible breaking of the epidermis as well as external browning. Not only was this heat damage accentuated when the fruit was more mature, but also when the HWT was carried out at higher temperatures and for longer. After the shelf life period, these physical disorders were intensified and there appeared internal browning and compacting of the outer $1 \mathrm{~cm}$ flesh tissue caused by dehydration. This compacting of fruit flesh, which was more intensive in heavily cracked areas, interfered with the evaluation of the effect of HWT on the reduction of the softening associated with $\mathrm{CI}$, because these areas of compacted flesh were reflected in high values of firmness. Therefore, the values of firmness in these cases cannot be used as an indicator of CI.

The presence of browning associated with the application of heat treatments to persimmon was similar with that previously reported for nonastringent cv. Fuyu by Woolf et al. (1997a), Burmeister et al. (1997), and Lay-Yee et al. (1997), who observed, like in our case, an increase in the incidence and severity of this alteration as the temperatures used rose and treatment time increased.

Skin cracking in persimmon has not previously been associated with HT; however, some cultivars such as Yubeni and Fuyu (Yamada et al., 2003) or Jiro and Izu (Sato and Yamada, 2003) show a natural tendency to suffer cracking at the calyx end. In other fruit, skin cracking has been associated with different factors; in tomato for example, it was associated with sharp changes of humidity and also with increasing total soluble solids (TSS) (Peet, 1992) as well as high soluble pectin content (Gao, 1995). Based on this, an increasing TSS content, fruit softening, and therefore an increase in the amount of soluble pectin as the persimmon matures (Salvador et al., 2007) could be some of the factors that explain why 'Rojo Brillante' shows a greater tendency to develop skin cracking after HWT application the more mature it gets.

In summary, the results obtained in this work report the conditions, fruit maturity stage, duration, and temperature of application in which hot water treatments improve the storage life of persimmon 'Rojo Brillante'. 


\section{Literature Cited}

Arnal, L. and M.A. Del Río. 2004. Effect of cold storage and removal astringency on quality of persimmon fruit (Diospyros kaki, L.) cv. 'Rojo Brillante'. Food Sci. Technol. Intl. 10:179185

Burmeister, D.M., S. Ball, S. Green, and A.B. Woolf. 1997. Interaction of hot water treatments and controlled atmosphere storage on quality of 'Fuyu' persimmons. Postharvest Biol. Technol. 12:71-81.

Collins, R.J. and J.S. Tisdell. 1995. The influence of storage time and temperature on chilling injury in Fuyu and Suruga persimmon (Diospyros kaki L.) grown in subtropical Australia. Postharvest Biol. Technol. 6:149-157.

Gao, Z.H. 1995. Studies on correlations of tomato firmness and crack with other characters. Acta Hort. 402:380-387.

Lay-Yee, M., S. Ball, S.K. Forbes, and A.B. Woolf. 1997. Hot-water treatment for insect disinfestation and reduction of chilling injury of 'Fuyu' persimmon. Postharvest Biol. Technol. 10:8187.
Mulas, M. and M. Schirra. 2007. The effect of heat conditioning treatments on the postharvest quality of horticultural crops. Stewart Postharvest Rev. 3:1-6.

Peet, M.M. 1992. Fruit cracking in tomato. HortTechnology 2:216-219, 222-223.

Salvador, A., L. Arnal, C. Besada, V. Larrea, A. Quiles, and I. Pérez-Munuera. 2007. Physiological and structural changes during ripening and deastringency treatment of persimmon cv. 'Rojo Brillante'. Postharvest Biol. Technol. 46:181-188.

Salvador, A., L. Arnal, J.M. Carot, C.P. Carvalho, and J.M. Jabaloyes. 2006. Influence of differen factors on firmness and color evolution during the storability of persimmon cv. 'Rojo Brillante'. J. Food Sci. 71:169-175.

Salvador, A., L. Arnal, A. Monterde, and J. Cuquerella. 2004. Reduction of chilling-injury symptoms in persimmon cv. 'Rojo Brillante' by 1-MCP. Postharvest Biol. Technol. 33:285291.

Salvador, A., L. Arnal, A. Monterde, C. Passaro, and J.M. Martínez-Jávega. 2005. Effect of harvest date in chilling-injury development of persimmon fruit. Acta Hort. 687:399403.

Sato, A. and M. Yamada. 2003. Leading persimmon cultivars for commercial production and breeding targets in Japan. Acta Hort. 601:2530 .

Woolf, A.B., S. Ball, K.J. Spooner, M. Lay-Yee, I.B. Ferguson, C.B. Watkins, A. Gunson, and S.K. Forbes. 1997a. Reduction of chilling injury in the sweet persimmon 'Fuyu' during storage by dry air heat treatments. Postharvest Biol. Technol. 11:155-164.

Woolf, A.B., E.A. MacRae, K.J. Spooner, and R.J. Redgwell. 1997b. Changes to physical properties of the cell wall and polyuronides in response to heat treatment of 'Fuyu' persimmon that alleviate chilling injury. J. Amer. Soc. Hort. Sci. 122:698-702.

Yamada, M., H. Yamane, A. Kurihara, K. Nagata, A. Sato, T. Kishi, R. Matsumoto, K. Yoshinaga N. Hirakawa, H. Iwanami, M. Kakutani, T. Ozawa, T. Sumi, T. Hirabayashi, K. Kanato, and I. Nakajima. 2003. New Japanese persimmon cultivar 'Yubeni'. Bul. of the Natl. Inst of Fruit Tree Sci. 2:65-75. 